\title{
USE OF CARBON FIBER COMPOSITE MOLECULAR SIEVES FOR AIR SEPARATION
}

Fred Baker, Nidia Gallego, Cristian Contescu, and Tim Burchell 
Metals and Ceramics Division

\title{
USE OF CARBON FIBER COMPOSITE COLECULAR SIEVES FOR AIR SEPARATION
}

\author{
F. S. Baker, N C. Gallego, C. Contescu, and T. D. Burchell
}

September 2005

Prepared for

Fossil Energy AR\&TD Materials Office

Prepared by

OAK RIDGE NATIONAL LABORATORY

Oak Ridge, Tennessee 37831-6087

managed by

UT-BATTELLE, LLC

for the

U.S. DEPARTMENT OF ENERGY

under contract DE-AC05-00OR22725 


\section{CONTENTS}

$\underline{\text { Page }}$

1. USE OF CARBON FIBERS COMPOSITE MOLECULAR SIEVES

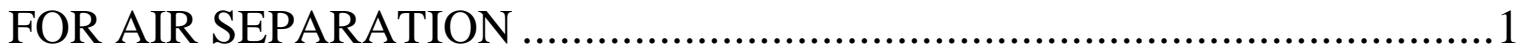

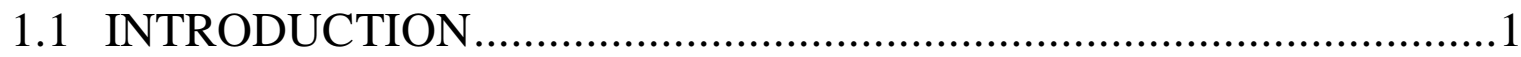

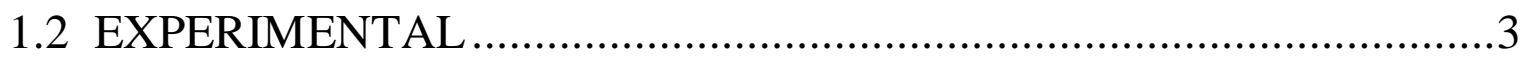

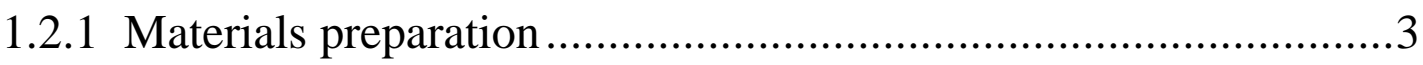

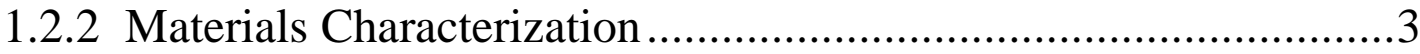

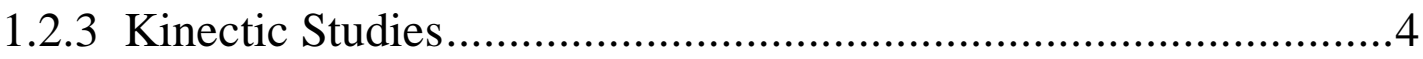

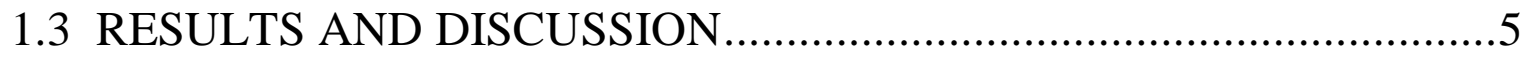

1.3.1 Summary of preliminary Findings ...............................................

1.3.2 $\mathrm{N}_{2}$ and $\mathrm{CO}_{2}$ Adsorption Isotherm and Pore Size

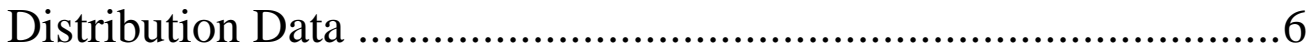

1.3.3 Dynamic $\mathrm{O}_{2}$ and $\mathrm{N}_{2}$ Adsorption Studies .................................

1.4 CONCLUSIONS AND FUTURE WORK …...................................... 10

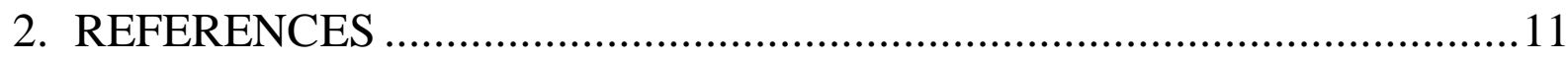

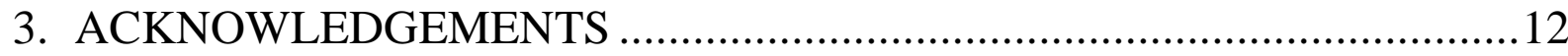




\section{LIST OF TABLES}

$\underline{\text { Page }}$

1. Surface area and micropore volume data for activated Carbon fiber products 6

\section{LIST OF FIGURES}

1. SEM images showing the structure of CFCMS material..........................2

2. The major processing operations in the fabrication of

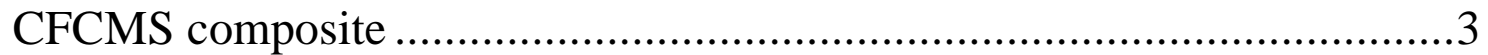

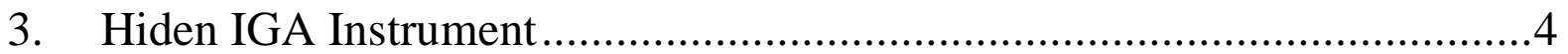

4. High pressure $\mathrm{O}_{2}$ and $\mathrm{N}_{2}$ isotherms on CFCMS at 294K .......................4

5. $\mathrm{N}_{2}$ and $\mathrm{CO}_{2}$ adsorption isotherms as a function of carbon

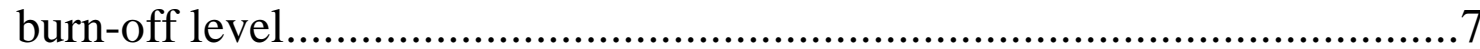

6. Rates of $\mathrm{O}_{2}$ and $\mathrm{N}_{2}$ adsorption on activated carbon fiber products .............8

7. Rates of $\mathrm{O}_{2}$ and $\mathrm{N}_{2}$ adsorption at $294 \mathrm{~K}$ as a function of Carbon burn-off level ........................................................................... 9

8. Comparison of $\mathrm{CO}_{2}$ isotherms on lignin and pitch-based carbon fibers ....10 


\section{ABBREVIATIONS}

$\underline{\text { Terms }}$

BET Brunauer, Emmett, and Teller (theory) [14]

CFCMS carbon fiber carbon molecular sieve

ESA electrical swing adsorption

IGA Intelligent Gas Analyzer (Hidden Instruments term)

ORNL Oak Ridge National Laboratory

PSA pressure swing adsorption

SEM scanning electron microscopy

Gases

$\mathrm{CO}_{2} \quad$ carbon dioxide

$\mathrm{N}_{2} \quad$ nitrogen

$\mathrm{O}_{2} \quad$ oxygen

$\underline{\text { Units }}$

Bar barometric pressure ( $\equiv 0.1 \mathrm{MPa}$ or 1.01325 atmospheres)

${ }^{\circ} \mathrm{C} \quad$ degrees Celsius

$\mathrm{K}$ degrees Kelvin

MPa megapascal

$\mathrm{m}^{2} / \mathrm{g}^{-1} \quad$ square meters per gram

$\mathrm{mbar} / \mathrm{min} \quad$ millibar of pressure per minute

$\mathrm{mg} / \mathrm{min} \quad$ milligram per minute

nm nanometer

$\%$ percent

wt $\% \quad$ weight percent ( $\%$ of mass) 


\title{
USE OF CARBON FIBER COMPOSITE MOLECULAR SIEVES FOR AIR SEPARATION
}

\author{
Fred Baker, Nidia Gallego, Cristian Contescu, and Tim Burchell \\ Carbon Materials Technology Group \\ Oak Ridge National Laboratory
}

\section{EXECUTIVE SUMMARY}

A novel adsorbent material, "carbon fiber composite molecular sieve" (CFCMS), has been developed by the Oak Ridge National Laboratory. Its features include high surface area, large pore volume, and a rigid, permeable carbon structure that exhibits significant electrical conductivity. The unique combination of high adsorptive capacity, permeability, good mechanical properties, and electrical conductivity represents an enabling technology for the development of novel gas separation and purification systems. In this context, it is proposed that a fast-cycle air separation process that exploits a kinetic separation of oxygen and nitrogen should be possible using a CFCMS material coupled with electrical swing adsorption (ESA).

The adsorption of $\mathrm{O}_{2}, \mathrm{~N}_{2}$, and $\mathrm{CO}_{2}$ on activated carbon fibers was investigated using static and dynamic techniques. Molecular sieving effects in the activated carbon fiber were highlighted by the adsorption of $\mathrm{CO}_{2}$, a more sensitive probe molecule for the presence of microporosity in adsorbents. The kinetic studies revealed that $\mathrm{O}_{2}$ was more rapidly adsorbed on the carbon fiber than $\mathrm{N}_{2}$, and with higher uptake under equilibrium conditions, providing the fiber contained a high proportion of very narrow micropores. The work indicated that CFCMS is capable of separating $\mathrm{O}_{2}$ and $\mathrm{N}_{2}$ from air on the basis of the different diffusion rates of the two molecules in the micropore network of the activated carbon fibers comprising the composite material.

In response to recent enquires from several potential users of CFCMS materials, attention has been given to the development of a viable continuous process for the commercial production of CFCMS material. As part of this effort, work was implemented on characterizing the performance of lignin-based activated carbon fiber, a potentially lower cost fiber than the pitchbased fibers used for CFCMS production to date. Similarly, to address engineering issues, measurements were made to characterize the pressure drop of CFCMS as a function of carbon fiber dimensions and monolith density.

\subsection{INTRODUCTION}

A novel adsorbent material, carbon fiber composite molecular sieve (CFCMS), has been developed by the Oak Ridge National Laboratory (ORNL) [1-3]. Upon thermal activation, usually in $\mathrm{CO}_{2}$ or steam, the carbon fiber-based material develops a large micropore volume $\left(0.5-1.0 \mathrm{~cm}^{3} / \mathrm{g}\right)$ and high BET surface area $\left(1000-2200 \mathrm{~m}^{2} / \mathrm{g}\right)$. As shown in the scanning electron microscopy (SEM) image in Figure 1, the structure of CFCMS comprises carbon fibers, $\sim 10 \mu \mathrm{m}$ in diameter, bonded at their contact points to provide a continuous carbon skeleton that is electrically conductive. The structure is open and permeable, which allows fluids to readily flow 
through the material with minimal pressure drop. The unique combination of the open structure, microporosity, and electrical conductivity allows the material to be used in a regenerative, electrical swing adsorption (ESA) system [4-6].
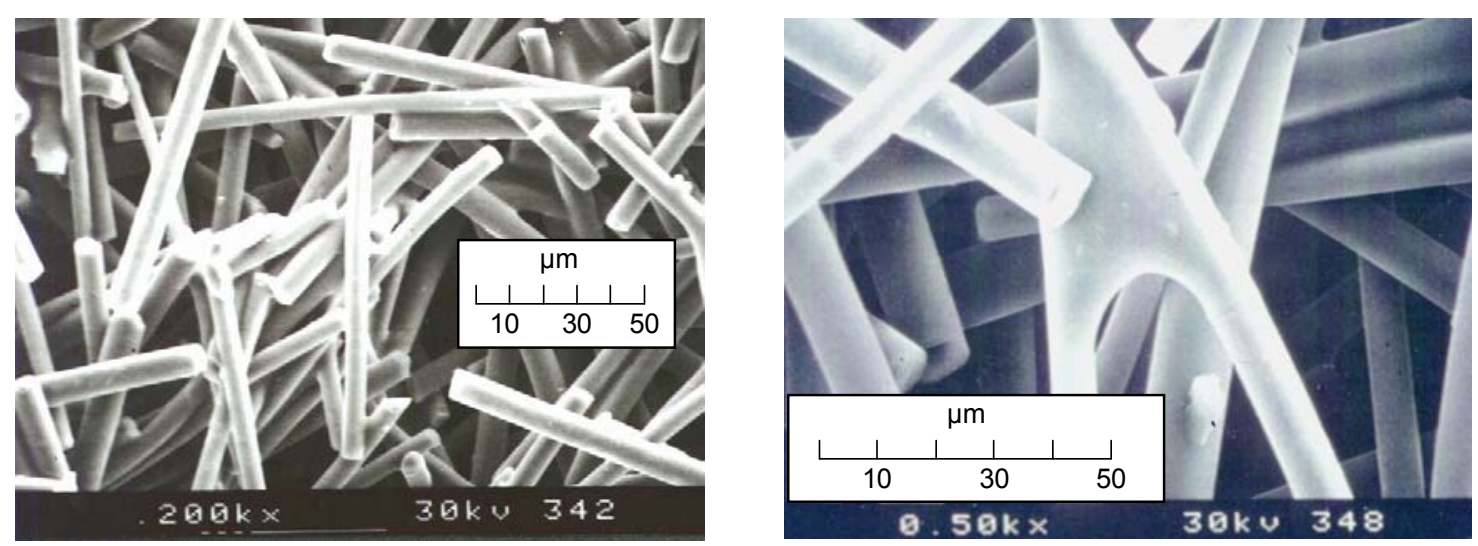

Figure 1 - SEM images showing the structure of CFCMS material

In essence, ESA is an electrical analog of pressure swing adsorption (PSA), whereby desorption of the adsorbate is facilitated by the passage of an electric current through the adsorbent to obtain resistive heating $[5,6]$. In this context, CFCMS represents an enabling technology for an ESA process in which efficient desorption could be achieved in the absence of pressure swings. The bottom line is that significant energy savings could be realized because the adsorption beds do not, in principle, require repressurization after each desorption step. This is consistent with the viewpoint of Jasra et al. [7], who in a review of the separation of gases by PSA noted that "although there is some room for improvement in the PSA process, the potential gains in process economics in the future are likely to come from the development of new and improved adsorbents".

CFCMS composites are produced using the process illustrated in Figure 2. Using a purpose-built vacuum slurry molding apparatus at ORNL, isotropic pitch-based carbon fibers are blended with a powdered phenolic resin at a typical ratio of four parts fiber to one part resin (by weight) in water. The dilute slurry is molded in a process somewhat similar to the forming of a pulp fiber mat in a papermaking process $[2,3]$. After molding, the green CFCMS composites are dried at $\sim 50^{\circ} \mathrm{C}$ for 24 hours and then heated to about $130^{\circ} \mathrm{C}$ for a further 24 hours to cure the phenolic resin. If a high bulk density material is required, the dried form is hot-pressed at a temperature of about $300^{\circ} \mathrm{C}$ prior to carbonization. The dried (or hot-pressed) composites are carbonized in a nitrogen atmosphere at $650^{\circ} \mathrm{C}$ for 4 hours, followed by thermal activation in a $\mathrm{CO}_{2}$ or steam atmosphere at $850^{\circ} \mathrm{C}$ until the desired level of carbon burn-off, i.e., activation, is attained (as measured by weight loss). The activated composite material is then machined to the desired final shape and dimensions. 


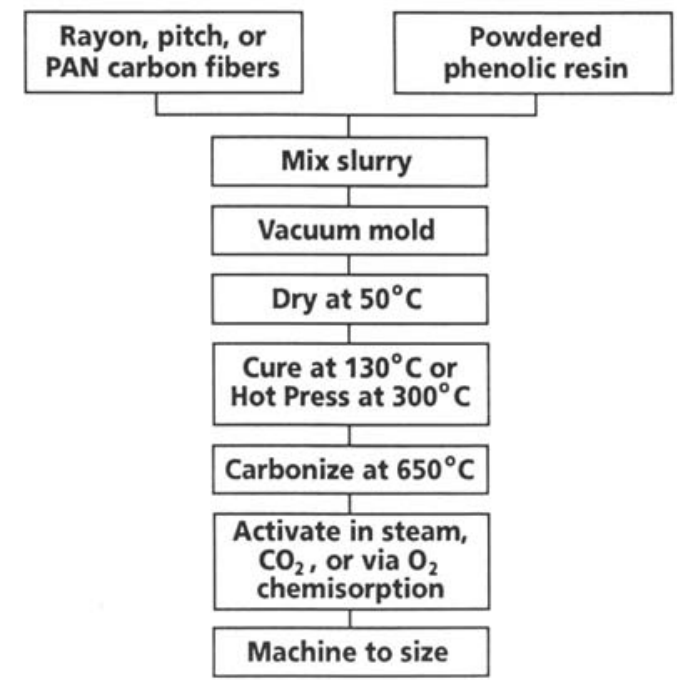

Figure 2 - The major processing operations in the fabrication of CFCMS composite [1-3]

Preliminary work demonstrated that CFCMS material has the potential for separating $\mathrm{O}_{2}$ and $\mathrm{N}_{2}$ in air [8-10]. However, the findings also indicated that a more efficient separation could be obtained if the micropore size distribution of the activated carbon fiber component could be better tailored for this purpose. Therefore, to provide the foundation for developing a suitable CFCMS material, a series of isotropic pitch-based activated carbon fiber products was prepared in which the degree of activation of the fiber was varied in the range of 5-30\% (carbon burn-off). The pore size distributions of these products were characterized, and correlated with the kinetics of adsorption of $\mathrm{O}_{2}$ and $\mathrm{N}_{2}$, respectively, on the activated carbon fibers. The findings are summarized here.

\subsection{EXPERIMENTAL}

\subsubsection{Materials Preparation}

On a Hiden Analytical "Intelligent Gravimetric Analyzer" (IGA) instrument (Figure 3), $140 \mathrm{mg}$ samples of isotropic pitch-based carbon fibers (Anshan East Asia Carbon Co.) were activated to the desired level of carbon burn-off, as measured by weight loss, at a temperature of $835^{\circ} \mathrm{C}$ in an atmosphere of pure $\mathrm{CO}_{2}$ (at ambient pressure).

\subsubsection{Materials Characterization}

The surface area and pore size distribution of representative samples of the activated carbon fibers were characterized by nitrogen adsorption at $77 \mathrm{~K}\left(-196^{\circ} \mathrm{C}\right)$ and $\mathrm{CO}_{2}$ adsorption at $273 \mathrm{~K}$ $\left(0^{\circ} \mathrm{C}\right)$ using a Quantachrome Autosorb-1 instrument. Apparent surface areas were derived from the $\mathrm{N}_{2}$ and $\mathrm{CO}_{2}$ adsorption isotherms using the standard BET method [11,12]. Pore size distributions were calculated from the adsorption data by application of the density functional theory (DFT) approach $[13,14]$. Similarly, micropore volumes were estimated using the Dubinin-Astakov (DA) equation [12]. 


\subsubsection{Kinetic Studies}

Using the Hiden IGA instrument (Figure 3), dynamic measurements were made on the activated carbon fiber products, in which the adsorption of $\mathrm{O}_{2}$ and $\mathrm{N}_{2}$, respectively, was monitored as a function of time to examine the approach to equilibrium, during and after a constant-rate pressure rise from 0.001 to $0.1 \mathrm{MPa}(0.01$ to $1 \mathrm{bar}$ ). This pressure range was selected because the isotherms shown in Figure 4 for $\mathrm{O}_{2}$ and $\mathrm{N}_{2}$ adsorption at $294 \mathrm{~K}$ on a CFCMS material (10\% burn-off level) are steepest at low pressure, and therefore kinetic effects should be more easily observed [8-10].

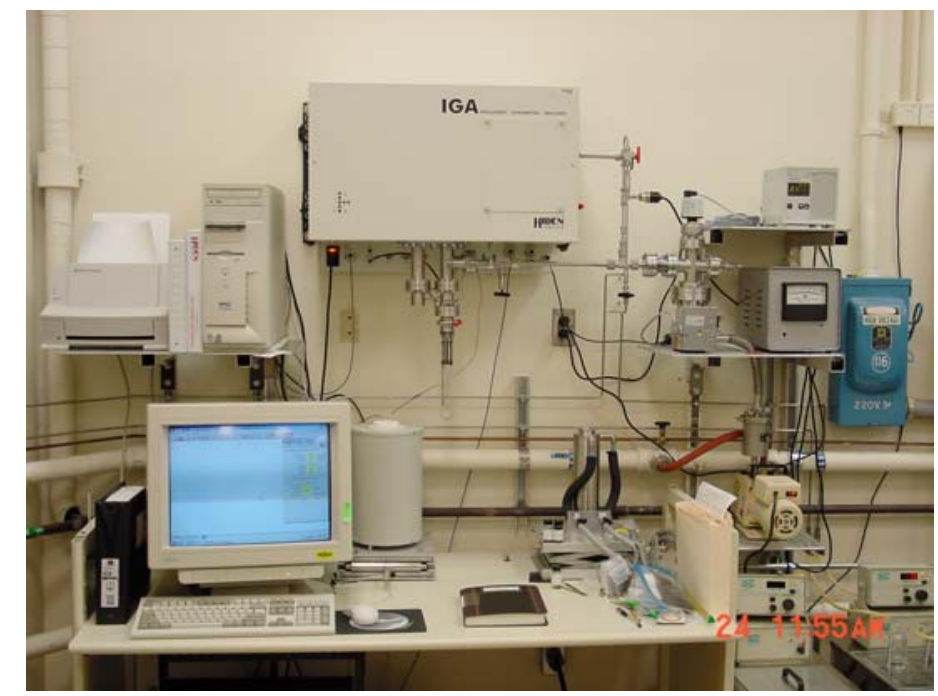

Figure 3 - Hiden IGA Instrument

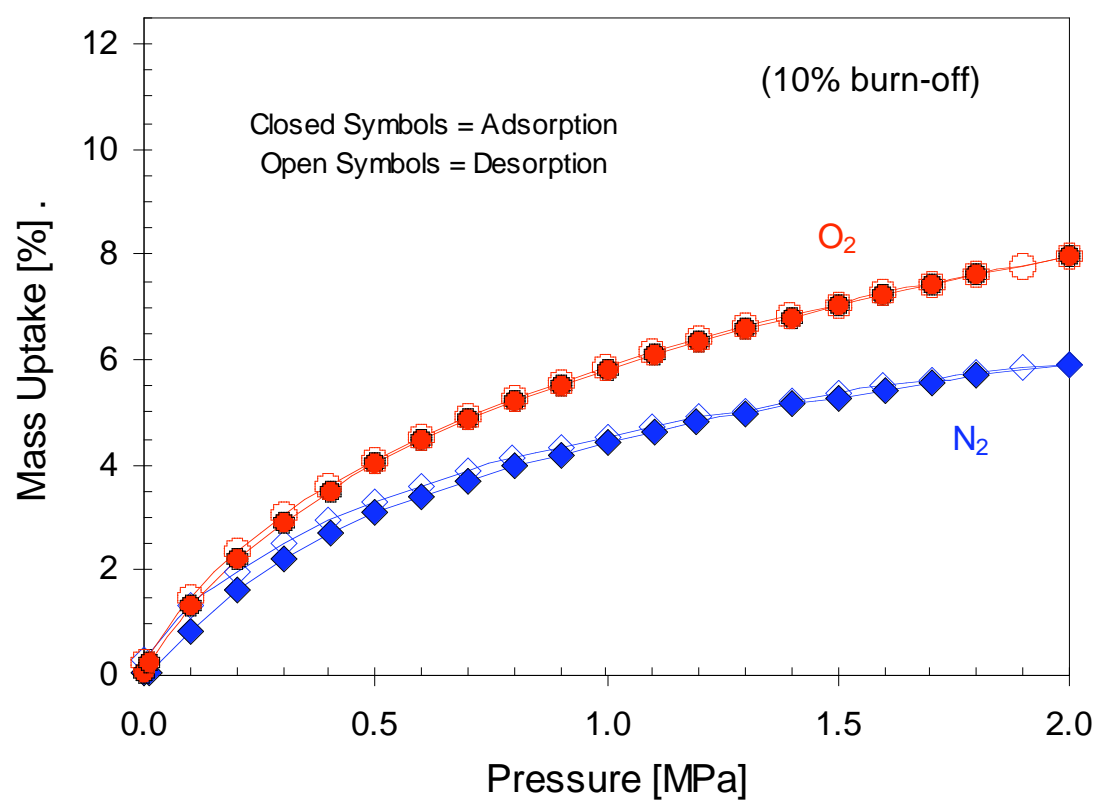

Figure 4 - High pressure $\mathrm{O}_{2}$ and $\mathrm{N}_{2}$ isotherms on CFCMS at $294 \mathrm{~K}$ 
The activated carbon fiber samples were outgassed under high vacuum $\left(<10^{-10} \mathrm{MPa}\right.$, or $10^{-9}$ bar $)$ at a temperature of $300^{\circ} \mathrm{C}$ immediately before the kinetic measurements of $\mathrm{O}_{2}$ and $\mathrm{N}_{2}$ adsorption.

\subsection{RESULTS AND DISCUSSION}

\subsubsection{Summary of Preliminary Findings}

In the preliminary work reported earlier [8-10], adsorption isotherms of pure $\mathrm{O}_{2}$ and $\mathrm{N}_{2}$, respectively, were determined on two CFCMS materials (carbon burn-off levels of 10 and 26\%, respectively) over a pressure range of $0-2 \mathrm{MPa}(0-20 \mathrm{bar})$, at temperatures of $294 \mathrm{~K}\left(21^{\circ} \mathrm{C}\right)$, $338 \mathrm{~K}\left(65^{\circ} \mathrm{C}\right)$, and $358 \mathrm{~K}\left(85^{\circ} \mathrm{C}\right)$. In keeping with the thermodynamics of adsorption, equilibrium uptake of each gas decreased with increasing temperature. Furthermore, on either a mass or molar basis, the equilibrium uptake of $\mathrm{O}_{2}$ on the CFCMS materials was greater than that of $\mathrm{N}_{2}$ (at each temperature). This is exemplified in Figure 4 above for $\mathrm{O}_{2}$ and $\mathrm{N}_{2}$ adsorption at $294 \mathrm{~K}$ on the CFCMS material with a carbon burn-off level of 10\%. At a pressure of $2 \mathrm{MPa}$, the uptakes of $\mathrm{O}_{2}$ and $\mathrm{N}_{2}$ on the CFCMS material were $\sim 8$ and $\sim 6 \mathrm{wt} \%$, respectively.

The low-pressure hysteresis exhibited by the $\mathrm{N}_{2}$ isotherm in Figure 4 is unusual, and may possibly be an artifact of the method of measurement. That is, even though the measurements were continuously made over almost two days, insufficient time was allowed for establishment of equilibrium during determination of the desorption isotherm at lower pressures. As is common practice in using computer-controlled instruments for gas adsorption measurements, a constant value for the "time-out" function was entered into the operating parameters of the IGA instrument; i.e., the elapsed time at which the IGA moves onto the determination of the next isotherm point regardless of whether it is still detecting a change in sample mass. A postmortem of the IGA data obtained in the preliminary work revealed that all the low pressure desorption points shown in Figure 4 for $\mathrm{N}_{2}$ adsorption on the CFCMS material were, in fact, based on mass values recorded when the time-out point at a given pressure was reached: albeit almost imperceptibly, sample mass was still declining at that point. Had the time-out point been set to a higher value, more gas may have desorbed at a given pressure, thereby decreasing, possibly eliminating the low-pressure hysteresis in the desorption isotherm.

Having said this, however, it should be noted that all the $\mathrm{O}_{2}$ and $\mathrm{N}_{2}$ isotherms obtained in the earlier work were determined using the same set of instrument operating parameters, including the value of the time-out point. Of particular note in this context is the fact that the corresponding isotherm in Figure 4 for $\mathrm{O}_{2}$ adsorption on the CFCMS material is almost totally reversible, showing only a very small degree of hysteresis at the lowest pressures. Furthermore, all isotherms for $\mathrm{N}_{2}$ and $\mathrm{N}_{2}$ adsorption, respectively, on the CFCMS materials at the higher temperatures of 338 and $358 \mathrm{~K}$ in the earlier work were fully reversible [8-10]. The salient point is that these observations indicated that the CFCMS material in question exhibited significant molecular sieving behavior between $\mathrm{N}_{2}$ and $\mathrm{O}_{2}$ at $294 \mathrm{~K}$. Because adsorption of $\mathrm{N}_{2}$ on the CFCMS material took place in very small pores, possibly of dimensions approaching that of the $\mathrm{N}_{2}$ molecule, it is a rate-controlled process with a positive temperature coefficient. When the temperature of the adsorption measurements was increased from 294 to 338K (and subsequently to $358 \mathrm{~K}$ ), the rate of diffusion of $\mathrm{N}_{2}$ molecules into and out of the small pores increased 
substantially and adsorption equilibrium was established within the time-out setting on the instrument, leading to fully reversible $\mathrm{N}_{2}$ isotherms at the higher temperatures. Similar activated diffusion effects have been reported much earlier for $\mathrm{N}_{2}$ adsorption on highly microporous activated carbons $[15,16]$.

Thus, the equilibrium uptake of $\mathrm{O}_{2}$ on the CFCMS materials examined in the preliminary work exceeded that of $\mathrm{N}_{2}$, and there were clear indications that the low carbon burn-off (10\%) material exhibited a strong molecular sieve effect. However, the differences between the equilibrium uptakes of $\mathrm{N}_{2}$ and $\mathrm{O}_{2}$ on the CFCMS material were small, and insufficient to indicate that the two molecules could be efficiently separated on the basis of their equilibrium adsorption behavior alone. Therefore, the work on the activated carbon fibers summarized here was carried out to provide the foundation for developing a suitable CFCMS material for air separation.

\subsection{2 $\mathrm{N}_{2}$ and $\mathrm{CO}_{2}$ Adsorption Isotherm and Pore Size Distribution Data}

The $\mathrm{N}_{2}$ and $\mathrm{CO}_{2}$ adsorption data obtained on the activated carbon fiber products are summarized in Table I.

Table 1 - Surface area and micropore volume data for activated carbon fiber products

\begin{tabular}{|c||ccccc|}
\hline Burn-off level $(\%)$ & 5 & 10 & 15 & 20 & 30 \\
\hline \hline $\mathrm{N}_{2}$ BET area $\left(\mathrm{m}^{2} \mathrm{~g}^{-1}\right)$ & 15 & 415 & $(790)$ & 730 & 960 \\
$\mathrm{CO}_{2}$ BET area $\left(\mathrm{m}^{2} \mathrm{~g}^{-1}\right)$ & 550 & 635 & 795 & 955 & 1170 \\
Micropore volume $(<2 \mathrm{~nm}, \mathrm{DFT})$ & 0.00 & 0.16 & $(0.32)$ & 0.29 & 0.38 \\
Micropore volume $(<2 \mathrm{~nm}, \mathrm{DA})$ & 0.00 & 0.19 & $(0.33)$ & 0.34 & 0.44 \\
\hline
\end{tabular}

With the exception of the two values shown in parentheses, the $\mathrm{N}_{2}$ and $\mathrm{CO}_{2}$ adsorption data show the expected trends in the development of surface area and micropore volume (as measured by $\mathrm{N}_{2}$ adsorption) with progressive increase in the degree of activation. It was noteworthy, however, that at the lowest burn-off level of 5\%, a very pronounced molecular sieving effect was observed between $\mathrm{N}_{2}$ and $\mathrm{CO}_{2}$. At $77 \mathrm{~K}$, nitrogen was unable to penetrate the ultrafine micropore structure developed under low burn-off conditions, resulting in an apparently very low BET surface area of $15 \mathrm{~m}^{2} \mathrm{~g}^{-1}$ and no measurable micropore volume. In contrast, carbon dioxide, at $273 \mathrm{~K}$, was able to enter the fine pores, revealing a significant surface area of $550 \mathrm{~m}^{2} \mathrm{~g}^{-1}$. The flat molecular shape of $\mathrm{CO}_{2}$ overcomes the slow diffusion or possible exclusion of $\mathrm{N}_{2}$ molecules from the smallest pores at $77 \mathrm{~K}$, thus revealing details of the smallest micropores $[17,18]$.

As pore width increased with carbon burn-off, congruence was obtained between the $\mathrm{N}_{2}$ and $\mathrm{CO}_{2}$ data. This is illustrated graphically in Figure 5, in which representative isotherms for $\mathrm{N}_{2}$ (at $77 \mathrm{~K}$ ) and $\mathrm{CO}_{2}$ (at $273 \mathrm{~K}$ ) adsorption on the activated carbon fiber products are shown as composite plots (for the 5, 10, 20, and 30\% burn-off levels, respectively). For the highest burn- 
off level of $30 \%$, the $\mathrm{N}_{2}$ and $\mathrm{CO}_{2}$ adsorption data essentially merge into the continuous type-I isotherm [19] shown in Figure 5d.

a) $5 \%$ Burn-off

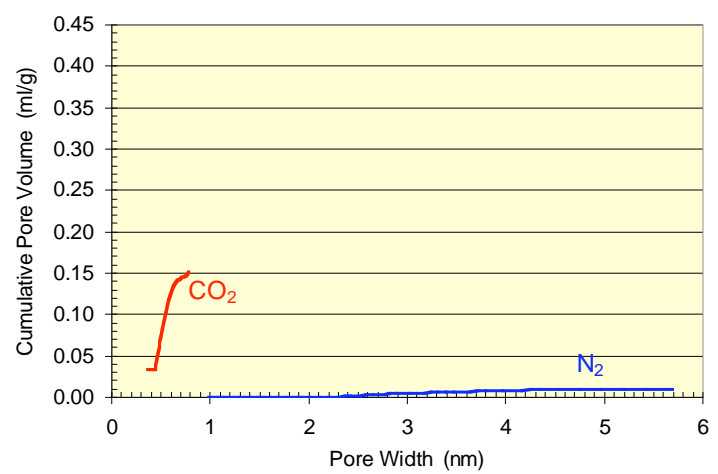

c) $20 \%$ Burn-off

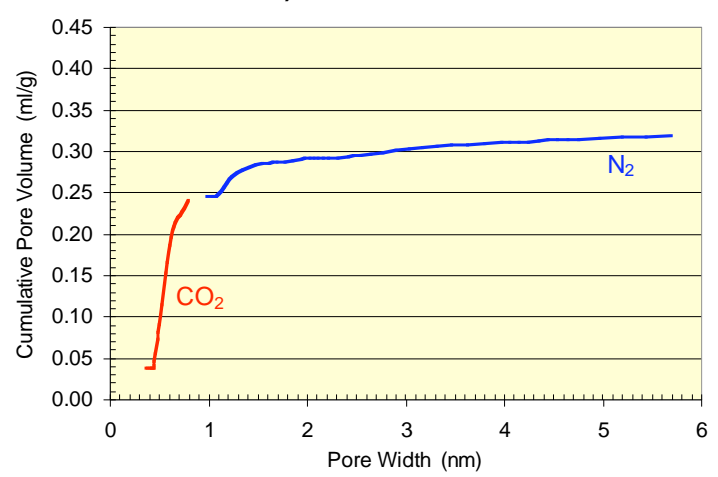

b) $10 \%$ Burn-off

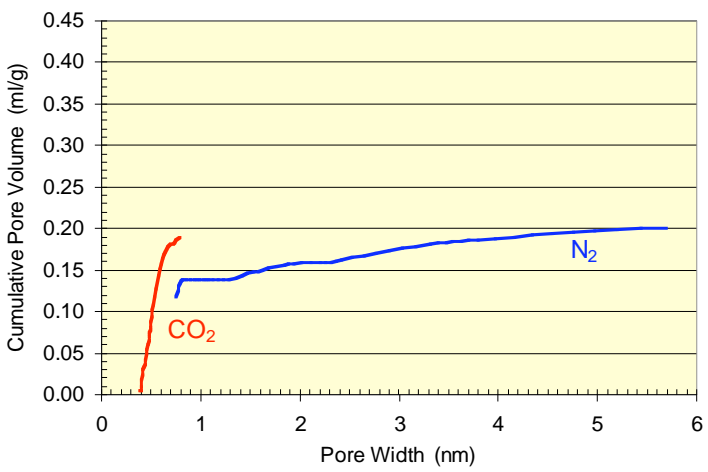

d) $30 \%$ Burn-off

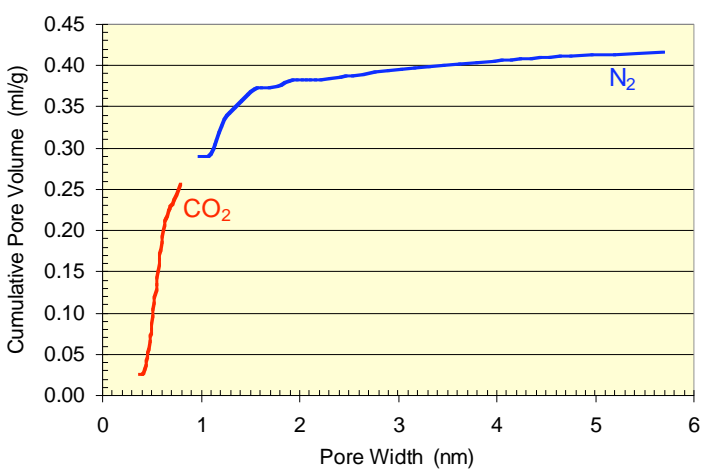

Figure $5-\mathrm{N}_{2}$ and $\mathrm{CO}_{2}$ adsorption isotherms as a function of carbon burn-off level

\subsubsection{Dynamic $\mathrm{O}_{2}$ and $\mathrm{N}_{2}$ Adsorption Studies}

The rates $\mathrm{O}_{2}$ and $\mathrm{N}_{2}$ adsorption, respectively, on the activated carbon fibers were measured at 294K. Each gas was dosed to the sample at two linear rates of pressure increase of 150 and 250 millibar/minute $(0.015$ and $0.025 \mathrm{MPa} /$ minute), respectively, over the pressure range of 0.01-1 bar (0.001-0.1 MPa). Representative plots are shown in Figure 6 for gas uptake as a function of time (at the $150 \mathrm{millibar} / \mathrm{minute}$ dosage rate) for carbon burn-off levels of 5, 15, and $30 \%$, respectively. The rates of $\mathrm{O}_{2}$ and $\mathrm{N}_{2}$ adsorption are summarized in Figure 7. 
a) $5 \%$ Burn-off

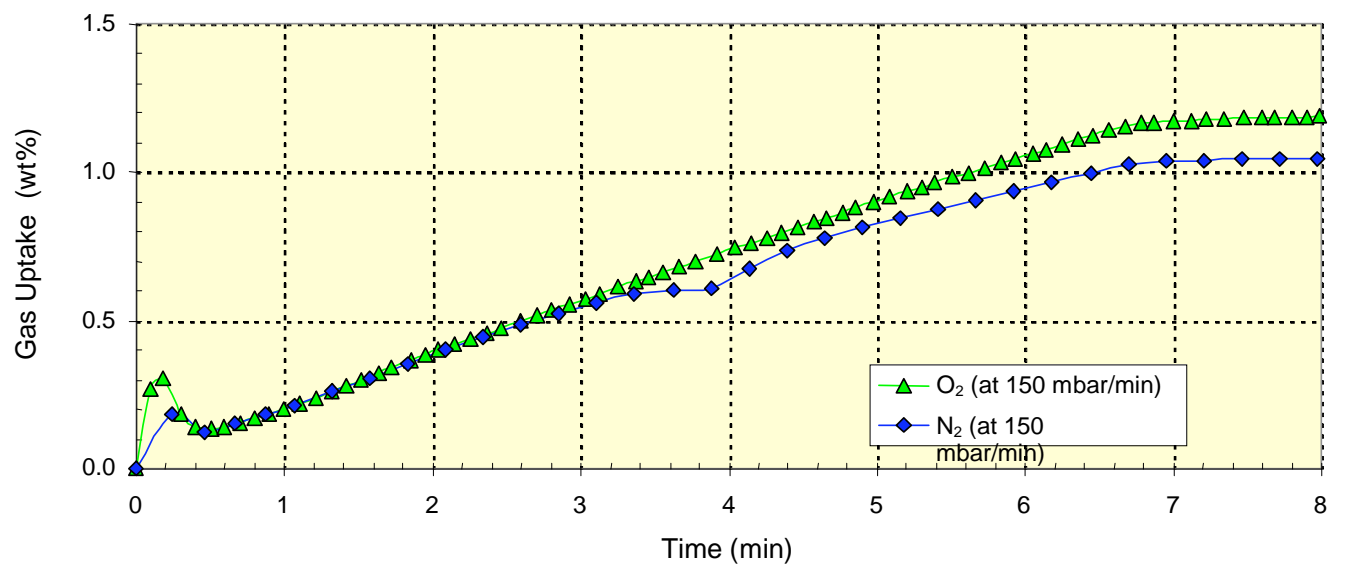

b) $15 \%$ Burn-off

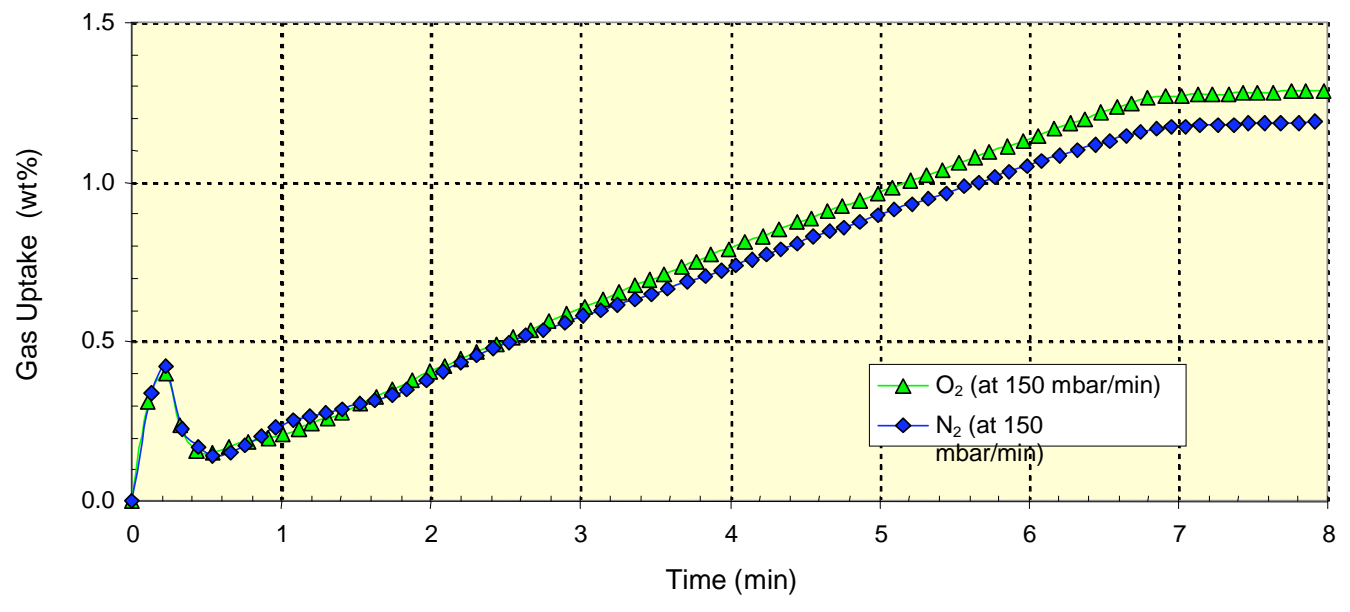

c) $30 \%$ Burn-off

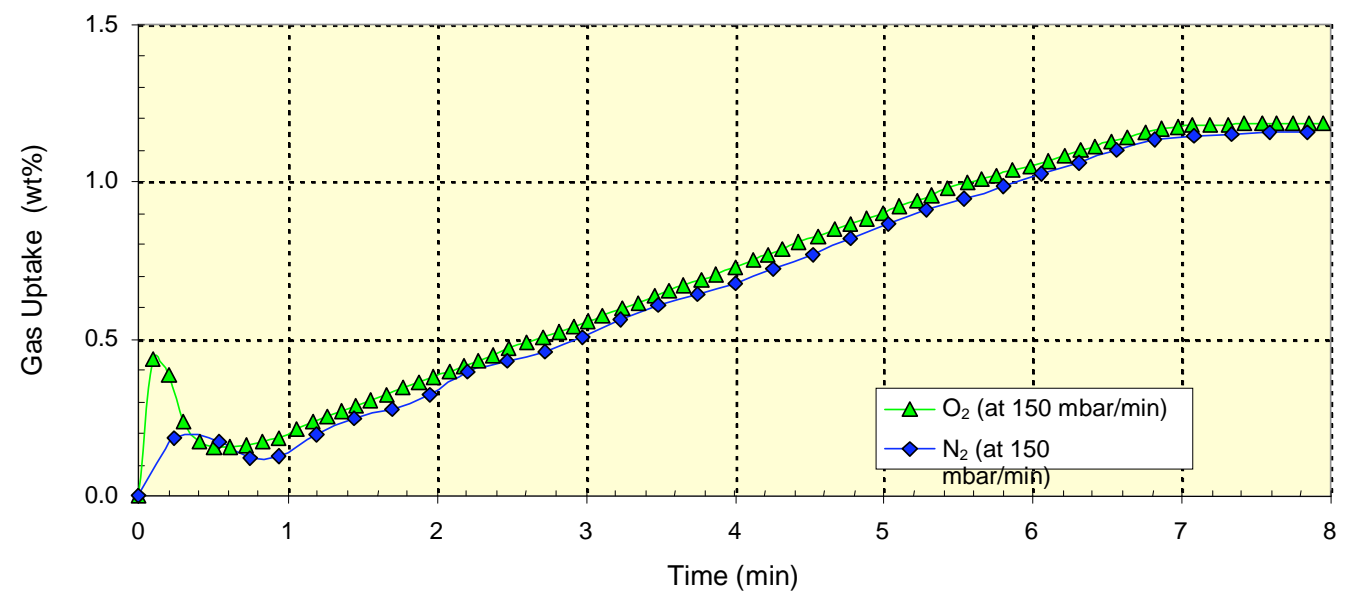

Figure 6 - Rates of $\mathrm{O}_{2}$ and $\mathrm{N}_{2}$ adsorption on activated carbon fiber products 


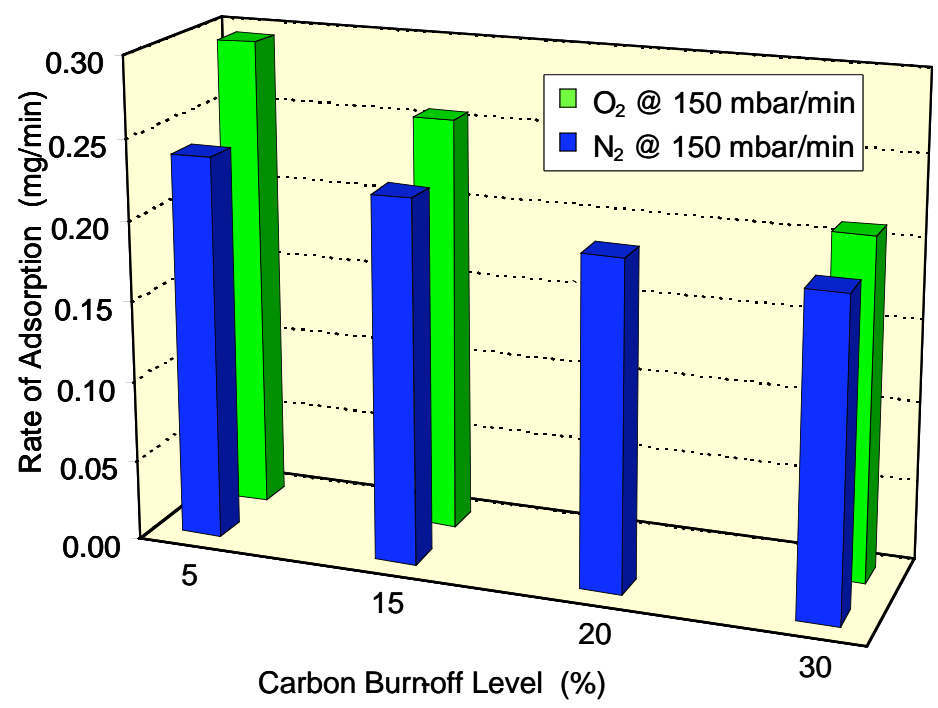

Figure 7 - Rates of $\mathrm{O}_{2}$ and $\mathrm{N}_{2}$ adsorption at $294 \mathrm{~K}$ as a function of carbon burn-off level

It is apparent from Figures 6 and 7 that the rate of $\mathrm{O}_{2}$ adsorption was markedly higher than that of $\mathrm{N}_{2}$, notably on the carbon fibers of lowest burn-off level of 5\% (Figure 6a) which exhibited a $25 \%$ higher rate of $\mathrm{O}_{2}$ adsorption (on a mass basis). The rate of adsorption of both $\mathrm{O}_{2}$ and $\mathrm{N}_{2}$ fell with progressive increase in the degree of activation of the carbon fibers. The amount of $\mathrm{N}_{2}$ adsorbed at equilibrium at 1 bar $(0.1 \mathrm{MPa})$ increased at the highest burn-off level of $30 \%$ (Figure 6b), indicative of the larger pore volume in this material. However, a consistent trend was not observed in the amount of either $\mathrm{O}_{2}$ or $\mathrm{N}_{2}$ adsorbed at equilibrium as a function of burnoff level, largely because the data for the 15\% burn-off material (Figure 6b) indicated a higher adsorption capacity than expected. Coupled with the independent nitrogen adsorption isotherm data shown in parentheses in Table 1, this indicates that measured level of burn-off of the "15\%" material may have been in error, and that it actually was substantially higher. Further work is necessary to resolve this question.

At both gas dosage rates, a sharp discontinuity was observed in the rate of $\mathrm{N}_{2}$ adsorption on the $5 \%$ burn-off carbon at a pressure of about $0.045 \mathrm{MPa}$ (corresponding to an elapsed time of about 3 minutes in Figure 6a). A similar change in rate of $\mathrm{N}_{2}$ adsorption was observed for the $15 \%$ burn-off carbon, but to a lesser degree, and was not observed for the highest burn-off level of $30 \%$. In contrast, a corresponding discontinuity in the rate of $\mathrm{O}_{2}$ adsorption was not observed for any of the activated carbon fiber products. The reason for this (reproducible) discontinuity in the rate of adsorption of $\mathrm{N}_{2}$ on the 5 and $15 \%$ burn-off carbon fiber products is not clear, but once again could be associated with a very pronounced molecular sieving effect in these materials. This observation is significant since the separation of $\mathrm{O}_{2}$ and $\mathrm{N}_{2}$ is a kinetic phenomenon, relying on the differences in the diffusion rates of the two molecules in narrow pore networks. The closer the pore width is to the molecular dimensions of the gasses the more significant the kinetic effects will be. Lower carbon burn-off level appears to be advantageous in this respect; higher levels $(>15 \%)$ increased micropore width to the point where molecular sieving effects were eliminated, which is counter-productive for air separation. 


\subsection{CONCLUSIONS AND FUTURE WORK}

Data for the adsorption of $\mathrm{O}_{2}, \mathrm{~N}_{2}$, and $\mathrm{CO}_{2}$, respectively, on isotropic pitch-based carbon fibers of varying degrees of activation demonstrated that a very low level of carbon burn-off is required to impart the molecular sieve properties in the carbon necessary for separation of $\mathrm{O}_{2}$ and $\mathrm{N}_{2}$ in air. $\mathrm{O}_{2}$ was more rapidly adsorbed on the activated carbon fiber than $\mathrm{N}_{2}$, and with higher uptake under equilibrium conditions, providing the fiber contained a high proportion of very narrow micropores. The presence of the very narrow micropores in the low burn-off carbon fibers was revealed through the adsorption of $\mathrm{CO}_{2}$, a more sensitive probe molecule than $\mathrm{N}_{2}$ for the presence of microporosity in adsorbents.

In addition to activation parameters, the adsorptive characteristics of activated carbon fibers are dependent on the nature of the precursor. In this context, lignin is a precursor known to produce highly microporous activated carbon products. In very preliminary work here, an activated carbon fiber was produced from a kraft hardwood, melt-spun lignin fiber. After stabilization and carbonization, the fiber was thermally-activated to a carbon burn-off level of $28 \%$. Characterization of the pore size distribution properties of the activated carbon fiber is on-going, but the $\mathrm{CO}_{2}$ isotherms shown in Figure 8 illustrate the potential of lignin as a precursor for the production of a molecular sieving carbon fiber for air separation.

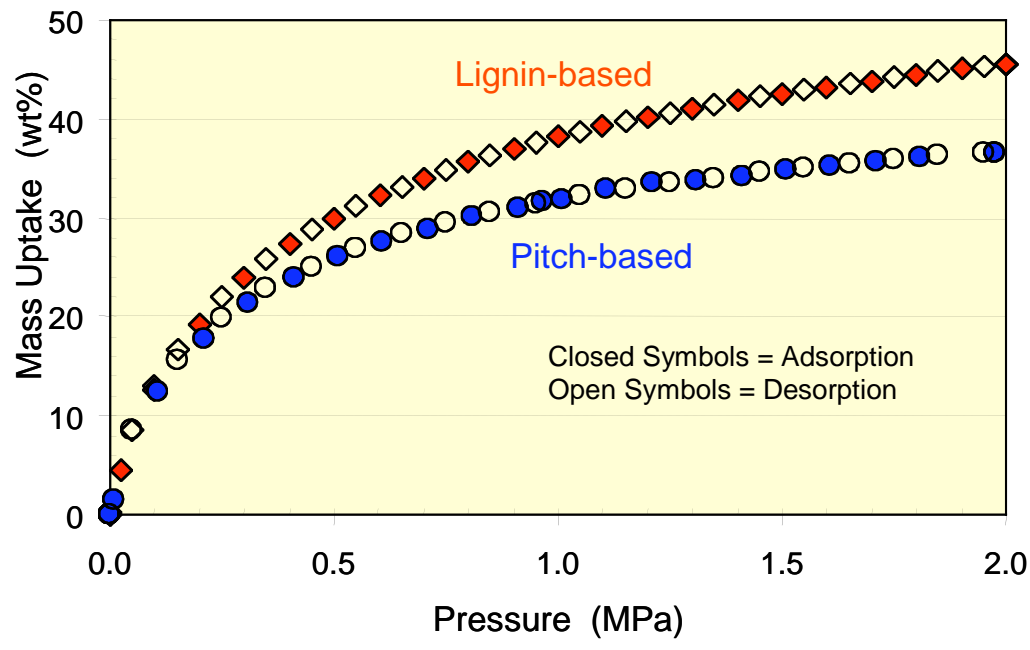

Figure 8 - Comparison of $\mathrm{CO}_{2}$ isotherms on lignin and pitch-based carbon fibers

The significantly higher $\mathrm{CO}_{2}$ adsorption capacity of the lignin-based activated carbon fiber is indicative of its more microporous structure compared to the pitch-based fiber of comparable burn-off level $(30 \%)$. Furthermore, based on the findings reported here for the pitch-based fibers, an even more microporous carbon fiber should be obtained from a lignin precursor by activating it to a lower level of burn-off; e.g., 5-10\%. Together with the examination of alternative activation techniques, this will be the subject of future work on the air separation project.

Overall, the findings reported here confirm that CFCMS has the potential for separating $\mathrm{O}_{2}$ and $\mathrm{N}_{2}$ from air on the basis of the different diffusion rates of the two molecules in the composite, 
but the degree of separation is dependent on developing an extensive network of very narrow micropores in the activated carbon fiber. This in turn is dependent on identifying and demonstrating alternative techniques to obtain a uniform degree of activation throughout the bulk of the composite material, especially if a low level of carbon burn-off is the key to achieving the requisite micropore size distribution. In this context, it is essential to use a combination of molecular probes, such as $\mathrm{CO}_{2}$ and $\mathrm{N}_{2}$, to properly characterize micropore size distribution.

To address engineering issues, a better understanding will be obtained of the factors that influence the permeability of CFCMS material, with the objective of reducing the pressure drop of the material for air separation and other applications. Similarly, alternative activated carbon composite forms will be evaluated, including honeycombs. Activated carbon honeycombs are used commercially for demanding gas phase applications, including capture of trace amounts of fugitive gasoline emissions from vehicles. The incorporation of highly microporous carbon fibers into such honeycombs has not been reported, however, and may have the potential of producing a very low pressure drop form that exhibits greater capacity and efficiency for air separation.

\section{REFERENCES}

1. T. D. Burchell, R. R. Judkins, M. R. Rogers, and A. M. Williams, "A Novel Process for the Separation of Carbon Dioxide and Hydrogen Sulfide for Gas Mixtures," CARBON, 35(9), pp. 1279-1294 (1997).

2. T. D. Burchell, C. E. Weaver, B. R. Chilcoat, F. Derbyshire, and M. Jagtoyen, "Activated Carbon Fiber Composite Material and Method of Making," United States Patent Number 6,030,698, February 29, 2000, Assigned to Lockheed Martin Energy Research Corporation.

3. T. D. Burchell, C. E. Weaver, B. R. Chilcoat, F. Derbyshire, and M. Jagtoyen, "Activated Carbon Fiber Composite Material and Method of Making," United States Patent Number 6,258,300, July 10, 2001, Assigned to UT-Battelle, LLC.

4. T. D. Burchell and R. R. Judkins, "A Novel Carbon Fiber Based Material and Separation Technology," Energy Conservation and Management, 38 Supplement, pp. S99-S104 (1997).

5. R. R. Judkins and T. D. Burchell, "Gas Separation Device Based on Electrical Swing Adsorption," United States Patent Number 5,972,077, October 26, 1999, Assigned to Lockheed Martin Energy Research Corporation.

6. K. A. Wilson, T. D. Burchell, and R. R. Judkins, "Carbon Fiber Composite Molecular Sieve Electrically Regenerable Air Filter Media," United States Patent Number 5,827,355, October 27, 1998, Assigned to Lockheed Martin Energy Research Corporation.

7. R. V. Jasra, N. V. Choudary, and S. G. T. Bhat, "Review: Separation of Gases by Pressure Swing Adsorption," Separation and Science Technology, 26, pp. 885-930 (1991).

8. T. D. Burchell, O. O. Omatete, N. C. Gallego, and F. S. Baker, "Novel Activated Carbon Composites for Air Separation," Proceedings of the 18th Annual Conference on Fossil Energy Materials, Knoxville, TN, June 2-4, 2004.

9. T. D. Burchell, O. Omatete, N. C. Gallego, and F. S. Baker, "A Preliminary Assessment of the Use of Carbon Fiber Composite Molecular Sieves for Air Separation," ORNL/TM-2004/182, September 2004. 
10. T. D. Burchell, O. Omatete, N. C. Gallego, and F. S. Baker, "Use of Carbon Fiber Composite Molecular Sieves for Air Separation," Adsorption Science \& Technology, 23(3), pp. 175-194 (2005).

11. S. Brunauer, P. H. Emmett, and E. Teller, "Adsorption of Gases in Multimolecular Layers," J. Am. Chem. Soc., 60, pp. 309-319 (1938).

12. S. J. Gregg and K. S. W. Sing, Adsorption, Surface Area and Porosity, $2^{\text {nd }}$ Edition, Academic Press, London, 1982.

13. C. Lastoskie, K. E. Gubbins, and N. Quirke, "Pore Size Distribution Analysis of Microporous Carbons: A Density Functional Theory Approach,” J. Phys. Chem., 97, 4786-4796 (1993).

14. J. Jagiello and M. Thommes, "Comparison of DFT Characterization Methods Based on $\mathrm{N}_{2}$, Ar, $\mathrm{CO}_{2}$, and $\mathrm{H}_{2}$ Adsorption Applied to Carbons with Various Pore Size Distributions," CARBON, 42(7), pp. 1227-1232 (2004).

15. H. Marsh and W. F. K. Wynne-Jones, "The Surface Properties of Carbon - I. The Effect of Activated Diffusion in the Determination of Surface Area," CARBON, 1, pp. 269-279 (1964).

16. F. Rodriguez-Reinoso, J. D. Lopez-Gonzalez, and C. Berenguer, "Activated Carbons from Almond Shells - I. Preparation and Characterization by Nitrogen Adsorption," CARBON, 20(6), pp. 513-518 (1982).

17. F. Rodriquez-Reinoso and A. Linares-Solano, "Microporous Structure of Activated Carbons as Revealed by Adsorption Methods," in Chemistry and Physics of Carbon, Edited by P. A. Thrower, Volume 21, pp.1-146, Marcel Dekker, New York (1988).

18. D. Lozano-Castello, D. Cazorla-Amoros, and A. Linares-Solano, "Usefulness of $\mathrm{CO}_{2}$ Adsorption at $273 \mathrm{~K}$ for the Characterization of Porous Carbons," CARBON, 42(7), pp. 1233-1242 (2004).

19. S. Brunauer, L. S. Deming, W. E. Deming, and E. Teller, "On a Theory of the van der Waals Adsorption of Gases," J. Amer. Chem. Soc., 62, 1723-1732 (1940).

\section{ACKNOWLEDGEMENTS}

Research sponsored by Office of Fossil Energy, U.S. Department of Energy, National Energy Technology Laboratory, under the Fossil Energy Advanced Research Materials Program, contract number DE-AC05-00OR22725 with UT-Battelle, LLC. 


\section{INTERNAL DISTRIBUTION}

1. F. S. Baker

2. E. E. Bloom

3. T. D. Burchell

4. C. Contescu

5. N. C. Gallego

6. R. R. Judkins

7. Central Research Library

8-9. ORNL Laboratory Records-OSTI

10. ORNL Laboratory Records-RC

\section{EXTERNAL DISTRIBUTION}

11. Fred M. Glaser, U. S. Department of Energy, FE-25/Germantown Building, 1000 Independence Ave., S.W., Washington, D.C. 20585-1290

12. Udaya Rao, U. S. Department of Energy, National Energy Technology Laboratory, 626 Cochrans Mill Road, P.O. Box 10940, Pittsburgh, PA 15236-0940

13. Robert Romanosky, Jr., U. S. Department of Energy, National Energy Technology Laboratory, 3610 Collins Ferry Road, P.O. Box 880, Morgantown, WV 26507-0880 